E-ISSN: 2664-2301 P-ISSN: 2664-2298 IJOGN 2021; 3(2): 17-21

Received: 09-04-2021 Accepted: 12-05-2021

\section{Sapna Pathania}

Msc Nursing, Obstetrics and Gynaecological Nursing,

Saraswati Nursing Institute, Kurali, Chandigarh, Ldhori, Nurpur, Kangra, Himachal Pradesh, India

\section{Dr. Rajinder Singh} Senior Resident, S.M.G.S. Hospital Shalamr, GMC Jammu, Jammu \& Kashmir, India

\section{Sheetal Kumari}

Senior Staff Nurse, S.M.G.S. Hospital Shalamar, GMC Jammu, India
Corresponding Author: Sapna Pathania Msc Nursing, Obstetrics and Gynaecological Nursing, Saraswati Nursing Institute, Kurali, Chandigarh, Ldhori, Nurpur, Kangra, Himachal Pradesh, India

\section{A study to assess the women's perception of respectful maternity care among post natal mother's admitted in selected hospitals of Punjab}

\author{
Sapna Pathania, Dr. Rajinder Singh and Sheetal Kumari
}

DOI: $\underline{\text { https://doi.org/10.33545/26642298.2021.v3.i2a.68 }}$

\begin{abstract}
Respectful maternity care is a universal human right. The study is conducted to assess the women's perception of respectful maternity care and to observe the facilities related to respectful maternity care (RMC) available at selected hospitals of Punjab. The quantitative approach and descriptive design is used. Data was collected by using purposive sampling technique from 200 postnatal mothers admitted in three different hospitals. Modified Respectful maternity care scale and observational checklist was used to collect the data. Findings revealed that 57(28.5\%) women received poor Respectful Maternity Care and 85(42.5\%) received average whereas 58(29\%) women received good Respectful Maternity Care. In Hospital A 64.3\%, Hospital B (50\%) facilities whereas in hospital C (71.4\%) facilities were present in term of RMC . The study concluded that childbearing women deserve respectful maternity care. There is still need to implement proper policies and awareness related to respectful maternity care in health facilities.
\end{abstract}

Keywords: Respectful maternity care, health facilities, women perception

\section{Introduction}

Respectful maternity care (RMC) is not only a great important part of quality of care it is a human right. In 2016, WHO published new guidelines for improving the quality of care for mothers and new- born during pregnancy and child-birth in health facilities, which included an enlarge attention on respect and maintain the dignity ${ }^{[1]}$. "Respectful Maternity Care is an important issue for a country like India where 45,000 women die in pregnancy and childbirth each year, accounting for $17 \%$ of all maternal deaths worldwide ${ }^{[2]}$. The study was conducted to assess the women's perception of respectful maternity care among postnatal mothers and to observe the facilities related to respectful maternity care available at the selected hospitals of Punjab.

\section{Materials and methods}

Quantitative research approach with descriptive survey design was used. The study was conducted on 200 postnatal mothers admitted in postnatal wards of selected hospitals (civil hospital Kharar, civil hospital 6 phase and civil hospitals Roopnagar). Data was collected by using Purposive sampling technique. The tool was prepared on the basis of the objectives of the study. Tool was divided into three main sections. It includes:

Section-1:-socio demographic profile sheet - it consists of 10 items. It includes age in year, education, residence, Religion, Income, Occupation, Caste, Parity, Modes of delivery, Delivery conducted by.

Section-2:-Ephrem D Sheferaw Respectful maternity care Scale used. It has four determinants. with permission of researcher three component were added and modified. .It include friendly/dignified care, Abuse free care, Timely care, discrimination free care, confidentiality and privacy, detained or confined against will.

Section-3:-It is self structured Observational check list to observe the facilities related to respectful maternity care available at the selected hospitals.

Content validity of the tool was determined by the expert's opinion on the relevance of items. 
Socio demographic data sheet and the modified tool of Respectful maternity care, Observational Check list Performa was submitted to 6 experts in the field of nursing and their suggestions were accepted and incorporated. The reliability of the instrument was established by administering the tool to top 10 patient. Split half method was used and tool was found to be reliable $(p=0.7)$. The reliability of the tool 1 i.e. modified RMC scale $\mathrm{k}=0.76$, tool 2 i.e. observational checklist is $\mathrm{k}=0.6$. Pilot study was conducted on 10 subjects at selected hospitals of Punjab. Informed consent was taken from the subjects. Ethical approval for the study obtained from Ethical Committee of
Saraswati Nursing Institute.

\section{Results}

Data were analyzed by using SPSS 16.0 statistics. Data gathered was analyzed by using descriptive statistic on the basis of the objectives of the study. The data analysis was organized as follow:-

Part A: Socio-demographic profile of the study subjects.

Part B: Modified Respectful maternity care scale to assess the women perception of RMC.

Part C: Observational check list to observe the facilities of hospital in terms of RMC.

\section{Section-1}

Table 1: Frequency and Percentage Distribution of Subjects As Per Their Socio-Demographic Variables (N=200)

\begin{tabular}{|c|c|c|}
\hline Demographic Variables & Category & $\mathbf{f}(\%)$ \\
\hline \multirow{4}{*}{ Age (in year) } & $15-19$ & $04(2.0)$ \\
\hline & $20-24$ & $105(52.5)$ \\
\hline & $25-29$ & $77(38.5)$ \\
\hline & $>30$ & $14(7.0)$ \\
\hline \multirow{4}{*}{ Education } & No formal Education & $48(24.0)$ \\
\hline & Primary Education & $76(38.0)$ \\
\hline & Secondary Education & $43(21.5)$ \\
\hline & Graduate or above & $33(16.5)$ \\
\hline \multirow{2}{*}{ Residence } & Rural & $92(46.0)$ \\
\hline & Urban & $108(54.0)$ \\
\hline \multirow{3}{*}{ Religion } & Sikh & $54(27.0)$ \\
\hline & Hindu & $133(66.5)$ \\
\hline & Muslim & $13(6.5)$ \\
\hline \multirow{3}{*}{ Income (Rs) per month } & $5000-9000$ & $92(46.0)$ \\
\hline & $10000-14000$ & $96(48.0)$ \\
\hline & $>15000$ & $12(6.0)$ \\
\hline \multirow{2}{*}{ Occupation } & Employed & $25(12.5)$ \\
\hline & Housewife & $175(87.5)$ \\
\hline \multirow{3}{*}{ Caste } & General & $151(75.5)$ \\
\hline & SC & $44(22.0)$ \\
\hline & $\mathrm{OBC}$ & $05(2.5)$ \\
\hline \multirow{3}{*}{ Parity } & Primipara & $92(46.0)$ \\
\hline & Multipara & $97(48.5)$ \\
\hline & Grandmultipara & $11(5.5)$ \\
\hline \multirow{3}{*}{ Mode of delivery } & Vaginal delivery with episiotomy & $63(31.5)$ \\
\hline & Vaginal delivery without episiotomy & $119(59.5)$ \\
\hline & Caesarean section & $18(9.0)$ \\
\hline \multirow{2}{*}{ Delivery conducted by } & Doctor & $44(22.0)$ \\
\hline & Nurse & $156(78.0)$ \\
\hline
\end{tabular}

According to age, more than half of subjects 105 (52.5\%) were in the age group of 20-24 years. In case of education, majority of the subjects $76(38.0 \%)$ were studied upto primary education. As per residence, most of study subjects $108(54.0 \%)$ were belong to urban area. In religion, majority of the study subjects $133(66.5 \%)$ were belong to Hindu religion. Approximate equal to half $96(48.0 \%)$ had monthly income Rs.10, 000-14,000,92. Majority of study subjects 175(87.5) were housewives. Most of the subjects 151 $(75.5 \%)$ were General caste. Majority of subjects $92(46 \%)$ were primi-para and $119(59.5 \%)$ were delivered without episiotomy. Most of the subjects $156(78 \%)$ delivery conducted by nurses and 44(22\%) were delivered by doctors.

\section{Section-2}

Table 2: Mean, SD, \& Mean \% of study subjects as per their Perception of RMC (N=200)

\begin{tabular}{|c|c|c|}
\hline Determinants & Mean \pm SD & Mean\% \\
\hline Friendly care & $22.61 \pm 5.55$ & $80.75 \%$ \\
\hline Abuse Free care & $9.14 \pm 2.09$ & $76.16 \%$ \\
\hline Timely Care & $5.91 \pm 1.92$ & $73.87 \%$ \\
\hline Discrimination free care & $5.73 \pm 1.68$ & $71.62 \%$ \\
\hline Confidentiality and privacy & $7.35 \pm 1.3$ & $91.87 \%$ \\
\hline Informed Consent & $9.5 \pm 2.5$ & $59.37 \%$ \\
\hline Detention of facilities & $3.8 \pm 1.15$ & $95 \%$ \\
\hline
\end{tabular}


Table 2 depicts the mean, SD, and mean score of RMC determinant. The mean, SD, median and mean score of friendly care is $22.61 \pm 5.55,80.75 \%$, Abuse free care is $9.14 \pm 2.09$, $80.75 \%$, Timely care is $5.91 \pm 1.92,76.16 \%$,
Discrimination free care is $5.73 \pm 1.68,71.62 \%$, Confidentiality and privacy is $7.35 \pm 1.3,91.87 \%$, Informed Consent is $9.5 \pm 2.5,59.37$, Detention of facilities is $3.8 \pm$ $1.15,95 \%$.

Table 3: Item wise frequency and percentage distribution of study subjects as per their perception regarding friendly and dignified care $(\mathrm{N}=200)$

\begin{tabular}{|c|c|c|c|c|c|}
\hline \multicolumn{6}{|c|}{ Friendly/Dignified Care } \\
\hline S. No & Items & Strongly disagree & Disagree & Agree & Strongly Agree \\
\hline 1. & Care for me with kind approach & $12(6 \%)$ & $59(29.5 \%)$ & $128(64 \%)$ & $01(.5 \%)$ \\
\hline 2. & Treated me in a friendly manner & $13(6.5 \%)$ & $68(34 \%)$ & $118(59 \%)$ & $01(.5 \%)$ \\
\hline 3. & Talk positively about pain and relief & $21(10.5 \%)$ & $76(38 \%)$ & $102(51 \%)$ & $01(.5 \%)$ \\
\hline 4. & Showed concern and empathy & $21(10.5 \%)$ & $73(36.5 \%)$ & $106(53 \%)$ & $00(00 \%)$ \\
\hline 5. & Treated me with respect as an individual & $17(8.5 \%)$ & $70(35 \%)$ & $112(56 \%)$ & $01(.5 \%)$ \\
\hline 6. & Spoke to me in a language that I could understand & $11(5.5 \%)$ & $38(19 \%)$ & $148(74 \%)$ & $03(1.5 \%)$ \\
\hline 7. & Called me by name & $04(2 \%)$ & $13(6.5 \%)$ & $177(88.5 \%)$ & $06(03 \%)$ \\
\hline
\end{tabular}

The above table depict that out of total 128(64\%) were agree that health worker cared them with kind approach and similarly $118(59 \%)$ were agree that health worker treated them in a friendly manner, $102(51 \%)$ were agree that health worker talked positively about pain, 106(53\%) were agree that health worker showed her concern and empathy, where
$112(56 \%)$ were agree that health worker treated them with respect as an individual and $114(74 \%)$ were agree that health worker spoke to them in a language that they could understand, and $177(88.5 \%)$ were agree that health worker called me by name.

Table 4: Item wise frequency and percentage distribution of study subjects as per their perception regarding abuse free care. ( $\mathrm{N}=200)$

\begin{tabular}{|c|c|c|c|c|c|}
\hline \multicolumn{5}{|c|}{ Abuse Free Care } \\
\hline S. No & Items & Strongly disagree & Disagree & Agree & Strongly Agree \\
\hline 8. & Responded to my needs whether or not I asked & $11(5.5 \%)$ & $84(42 \%)$ & $101(50.5 \%)$ & $04(02 \%)$ \\
\hline 9. & Slapped me during delivery for different reasons & $08(04 \%)$ & $47(23.5 \%)$ & $135(67.5 \%)$ & $10(05 \%)$ \\
\hline 10. & Shouted at me because I had not done what I was told to do & $06(03 \%)$ & $128(64 \%)$ & $59(29.5 \%)$ & $07(3.5 \%)$ \\
\hline
\end{tabular}

Out of total 101(50.5\%) were agree that health workers responded to their need whether or not they asked, $135(67.5 \%)$ were agree that health workers slapped her during delivery for different reasons, 128(64\%) were disagree that health workers shouted at her because she hadn't done what she was told to do.

Table 5: Item wise frequency and percentage distribution of study subjects as per their perception regarding timely care $(\mathrm{N}=200)$

\begin{tabular}{|c|c|c|c|c|c|}
\hline \multicolumn{5}{|c|}{ Timely Care } \\
\hline S. No & Items & Strongly disagree & Disagree & Agree & Strongly Agree \\
\hline 11. & Waiting for a long time before receiving service & $06(03 \%)$ & $98(49 \%)$ & $91(45.5 \%)$ & $05(2.5 \%)$ \\
\hline 12. & Service provision was delayed due to health Facility internal problem & $04(02 \%)$ & $100(50 \%)$ & $93(46.5 \%)$ & $03(1.5 \%)$ \\
\hline
\end{tabular}

Out of total 98(49\%) were disagree that health workers kept waiting for a long time before receiving service and
$100(50 \%)$ were disagree that service provision was delayed due to health facility internal problems.

Table 6: Item wise frequency and percentage distribution of study subjects as per their perception regarding discrimination free care $(\mathrm{N}=200)$

\begin{tabular}{|c|c|c|c|c|c|}
\hline \multicolumn{6}{|c|}{ Discrimination Free Care } \\
\hline S. No & Items & Strongly disagree & Disagree & Agree & Strongly Agree \\
\hline 13. & Did not Treated me well because of my personal attributes. & $04(02 \%)$ & $107(53.5 \%)$ & $89(44.5 \%)$ & $00(00 \%)$ \\
\hline 14. & Insulted me and my companions due to my personal attributes & $03(1.5 \%)$ & $110(55 \%)$ & $85(42.5 \%)$ & $02(01 \%)$ \\
\hline
\end{tabular}

Out of total $107(53.5 \%)$ were disagree that health worker did not treated her well because of her personal attributes,
$110(55 \%)$ were disagree that health workers insulted her and companions due to their personal attributes.

Table 7: Item wise frequency and percentage distribution of study subjects as per their perception regarding confidentiality and privacy $(\mathrm{N}=200)$

\begin{tabular}{|c|c|c|c|c|c|}
\hline \multicolumn{5}{|c|}{ Confidentiality and Privacy } \\
\hline S. No & Items & Strongly disagree & Disagree & Agree & Strongly Agree \\
\hline 15. & Provided screen and curtains during examination & $08(04 \%)$ & $25(12.5 \%)$ & $167(83.5 \%)$ & $00(00 \%)$ \\
\hline 16. & Maintained privacy during delivery & $04(02 \%)$ & $21(10.5 \%)$ & $174(87 \%)$ & $01(0.5 \%)$ \\
\hline
\end{tabular}

Out of total $167(83.5 \%)$ were agree that health workers provided screen and curtains during examination, 174(87\%) were agree that health workers maintained privacy during delivery. 
Table 8: Item wise frequency and percentage distribution of study subjects as per their perception regarding right to information, informed consent $(\mathrm{N}=200)$

\begin{tabular}{|c|c|c|c|c|c|}
\hline \multicolumn{6}{|c|}{ Right To Information, Informed Consent } \\
\hline S. No & Items & Strongly disagree & Disagree & Agree & Strongly Agree \\
\hline 17. & Did not introduce self to me or to my birth Companion & $02(1.0 \%)$ & $151(75.5 \%)$ & $47(23.5 \%)$ & $00(00 \%)$ \\
\hline 18. & Did not obtain consent or permission prior to any Procedure & $05(2.5 \%)$ & $162(81 \%)$ & $33(16.5 \%)$ & $00(00 \%)$ \\
\hline 19. & $\begin{array}{c}\text { Did not give me periodic updates on status and } \\
\text { progress of my labour }\end{array}$ & $05(2.5 \%)$ & $166(83 \%)$ & $29(14.5 \%)$ & $00(00 \%)$ \\
\hline 20. & Birth companions to remain with me during delivery & $54(27 \%)$ & $69(34.5 \%)$ & $77(38.5 \%)$ & $00(00 \%)$ \\
\hline
\end{tabular}

Out of total 151(75.5\%) were disagree that health workers didn't introduce self to her or to her birth companion, $162(81 \%)$ were disagree that health worker did not obtain consent or permission prior to any procedure, $166(83 \%)$ were disagree that health workers didn't give her periodic updates on status and progress of her labor 77(38.5\%) were agree that health workers allow birth companion to remain with her during delivery $69(34.5 \%)$ were disagree.

Table 9: Item wise frequency and percentage distribution of study subjects as per their perception regarding detained or confided against will $(\mathrm{N}=200)$

\begin{tabular}{|c|c|c|c|c|c|}
\hline \multicolumn{5}{|c|}{ Detained or confined against will } \\
\hline S. No & Items & $\begin{array}{l}\text { Strongly } \\
\text { disagree }\end{array}$ & Disagree & Agree & Strongly Agree \\
\hline 21. & Andthreat you they will detain you and your baby from hospital. & $11(5.5 \%)$ & $27(13.5 \%)$ & $101(50.5 \%)$ & $61(30.5 \%)$ \\
\hline
\end{tabular}

Out of total 101(50.5\%) were agree that workers demand for informal baksheesh bribe and threat you they will detain their baby from hospital.

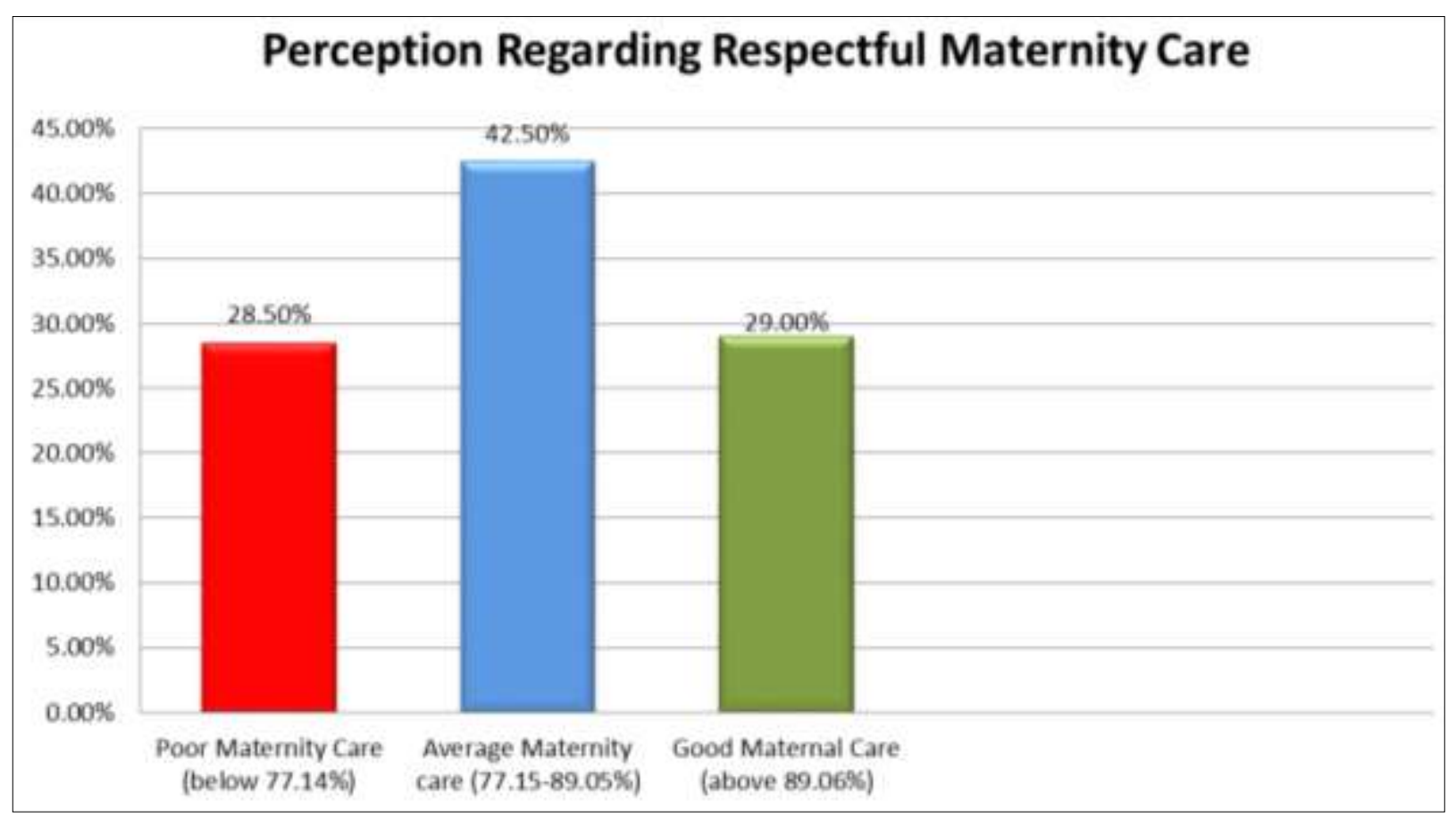

Fig 6: Percentage distribution of study subjects as per their perception regarding respectful maternity care.

Out of total $57(28.5 \%)$ study subjects received Poor Respectful Maternity Care, 85(42.5\%) study subject received Average Respectful Maternity Care and 58(29\%) study subject received Good Respectful Maternity Care.

\section{Section-3}

Table 10: Frequency and percentage Distribution of facilities related to Respectful Maternity in hospitals.

\begin{tabular}{|c|c|c|c|}
\hline Facilities & Hospital A & Hospital B & Hospital C \\
\hline No & $5(35.7 \%)$ & $07(50 \%)$ & $04(28.6 \%)$ \\
\hline Yes & $09(64.3 \%)$ & $07(50 \%)$ & $10(71.4 \%)$ \\
\hline
\end{tabular}

Table depict that Hospital A $05(35.7 \%)$ facilities related to RMC were not present and 09(64.3\%) facilities were present. In Hospital B $07(50 \%)$ facilities related to RMC were not present and 07(50\%) were present and comparatively $04(28.6 \%)$ in Hospital C the facilities related to RMC were not present and $10(71.4 \%)$ facilities were present. 


\section{Discussion}

The data shows that according to age, more than half of subjects $105(52.5 \%)$ were in the age group of 20-24 years. Majority of the subjects $76(38.0 \%)$ were studied up to primary, 48(24\%) were illiterate. Most of subjects $108(54.0 \%)$ were from urban area. Majority of the subjects133 (66.5\%) were belong to Hindu religion. Approximate equal to half $96(48.0 \%)$ had monthly income Rs.10,000-14,000. Majority of subjects 175(87.5) were Housewives. Most of the subject $151(75.5 \%)$ were General caste. Majority of subject $92(46 \%)$ were primipara and $97(48.5 \%)$ were multipara. Most of the subjects 119(59.5\%) were delivered with episiotomy. Most of the subjects $156(78 \%)$ delivery conducted by nurses. These finding were supported by in the study conducted by Alageswari A., Dr. A. Felicia Chitra reported that the majority of, 26(43.3\%) mothers were in the age group of 21-25 years, 53(88.3\%) mothers from Hindu religion, 26(43.3\%) mothers had education upto graduate, $39(65 \%)$ mothers were from joint family, 34(56.7\%) mothers were from rural areas, $37(61.7 \%)$ mothers were primi parity, 36(60\%) mothers had more than 5 members of health personnel during the delivery and $31(51.7 \%)$ mothers delivery conducted by male health personnel ${ }^{[3]}$.

The present study shows that $118(59 \%)$ were agree that health worker treated them in a friendly manner, 128(64\%) were disagree that health workers shouted at her because she hadn't done what she was told to do 98(49\%) were disagree that health workers kept waiting for a long time before receiving service. $107(53.5 \%)$ were disagree that health worker did not treated me well because of my personal attributes. $174(87 \%)$ were agree that health workers maintained privacy during delivery. $162(81 \%)$ were disagree that health worker did not obtain consent or permission prior to any procedure. total $101(50.5 \%)$ were agree that workers demand for informal baksheesh bribe and threat you they will detain. These finding were supported by in the study conducted by Alageswari A., Dr. A. Felicia Chitra reported that The majority of 58(96.7\%) mothers received friendly care, $51(85 \%)$ mothers reported abuse free care, $57(95 \%)$ mothers acknowledged timely care, 60(100\%) mothers received discrimination free care, and $49(81.7 \%)$ mothers received consented care and $47(78.3 \%)$ mothers acquired confidential care ${ }^{[3]}$.

\section{Conclusion}

The present study concluded that according to women's perception majority of the study subjects received average RMC and minority of subjects received poor and good RMC. Most of the facilities are also present in the hospitals in term of RMC. Respectful maternity care is universal right of pregnant women. There is still need to create awareness regarding 7 basic rights to women as well as health workers because a little respect and kind words helps to improve maternal care and proper utilization of services. The health provider should be aware of the rights and enrich them with quality based in care.

\section{References}

1. WHO. Recommendation on respectful maternity care during labour and childbirth $\mid$ RHL.

2. Bowser D, Hill K. Exploring Evidence for Disrespect and Abuse in Facility-Based Childbirth 57.

3. Kalyani. Effect of Awareness Programme on
Knowledge regarding Respectful Maternity Care, West Bangal. Journal of Family Medicine and Planning 2015.

4. Ndwiga C, Warren EC, Ritter J, et al. Exploring provider perspectives on respectful maternity care in Kenya. BMC 2017.

5. Wesson J, Hamunime N, Viadro C, et al. Provider and client perspectives on maternity care in Namibia. BMC 2018.

6. Alageswari A, Dash Mand, Felicia Chitra A. Knowledge and Perception of Postnatal Mothers on Respectful Maternity Care, Merit Research Journal of Medicine and Medical Sciences 2019:7(19). 